\title{
TERRITÓRIO E TERRITORIALIZAÇÃO: INCORPORANDO AS RELAÇÕES PRODUÇÃO, TRABALHO, AMBIENTE E SAÚDE NA ATENÇÃO BÁSICA À SAÚDE
}

\author{
TERRITORY AND TERRITORIALIZATION: INCORPORATING THE PRODUCTION, LABOR, \\ ENVIRONMENT, AND HEALTH RELATIONS IN PRIMARY HEALTH CARE
}

\author{
Alexandre Lima Santos ${ }^{1}$ \\ Raquel Maria Rigotto ${ }^{2}$
}

Resumo Este artigo tem como objetivo reunir subsídios teóricos para uma abordagem crítica das práticas de territorialização previstas na Atenção Básica à Saúde do Sistema Único de Saúde, bem como oferecer alguns elementos práticos que orientem sua ampliação, mediante a incorporação de novos olhares e das questões de saúde ambiental e do trabalhador, da forma como se apresentam no território. Para tanto, os conceitos de território e de territorialização são problematizados, com base em concepções diversas, a fim de dialogarem com as atribuições e desafios da Vigilância em Saúde e, especialmente, da Estratégia Saúde da Família. As relações produção-trabalho, saúde-ambiente são discutidas em sua relevância para a compreensão da dinâmica viva do processo saúde-doença no território. Por fim, são apresentados alguns passos que podem contribuir na reorganização e ampliação das práticas de territorialização na Atenção Básica à Saúde.

Palavras-chave territorialização; atenção básica à saúde; vigilância em saúde; saúde do trabalhador; saúde ambiental.
Abstract This article aims to bring together theoretical subsidies for a critical approach to the territorialization practices that are provided for in the Health System's Primary Health Care and to offer a few practical elements to guide its expansion through the incorporation of new views and environmental and worker health issues, as proposed in the territory. To achieve this, the territory and territorialization concepts are questioned based on different notions in order to dialogue with the attributions and challenges of Health Surveillance and, in particular, of the Family Health Strategy. The production-labor, health-environment relations are discussed with regard to their relevance for the understanding of the living dynamics of the health-disease process in the territory. Finally, a few steps that can contribute to the reorganization and expansion of the territorialization practices in Primary Health Care are presented.

Keywords territorialization; basic health care; health surveillance; occupational health; environmental health. 


\section{Introdução}

Muito se tem discutido a respeito da efetiva implementação das ações de saúde do trabalhador e de saúde ambiental no Sistema Único de Saúde (SUS), previstas em diversos dispositivos legais e normativos tanto da Constituição Federal quanto da Lei Orgânica da Saúde. Os debates acadêmicos, nas instâncias de controle social ou entre técnicos mostram, de forma inequívoca, que o primeiro passo está na inserção dessas ações na Atenção Básica à Saúde e na Estratégia Saúde da Família (ESF), portas de entrada do sistema e ponto-chave por meio do qual o SUS se encontra com o cotidiano de vida, saúde e doença de cidadãos e cidadãs. Entretanto, apesar do conjunto de esforços mais ou menos articulado, incluindo diversas iniciativas de capacitação de profissionais, ainda são muitas as dificuldades para a efetiva incorporação das relações produção-trabalho, saúde-ambiente nesse nível de organização do SUS.

Diversas são as causas possíveis de serem arroladas e debatidas. Neste artigo, vamos nos debruçar sobre as práticas de territorialização no SUS, como elemento importante e estratégico nesse processo. Pretendemos reunir subsídios teóricos para uma abordagem crítica do processo de territorialização previsto na Atenção Básica à Saúde do SUS, bem como oferecer alguns elementos práticos que orientem a sua ampliação, mediante a incorporação de novos olhares e das questões de saúde ambiental e de saúde do trabalhador, da forma como se apresentam no território.

Do ponto de vista metodológico, o texto é fruto da exploração da produção teórica sobre território e territorialização; da reflexão crítica sobre a práxis dos profissionais de saúde envolvidos na ESF - inclusive de um dos autores, e seus colegas de equipe; do esforço de preparar estudantes de Medicina, alunos da disciplina Saúde, Trabalho, Ambiente e Cultura, para reconhecerem adequadamente a dinâmica viva do processo saúdedoença no território onde irão atuar e com ele estabelecer vínculos; e do desejo de encontrar pontes entre as práticas de saúde do trabalhador e de saúde ambiental, para que se fortaleçam reciprocamente e efetivamente aconteçam no SUS.

A territorialização representa importante instrumento de organização dos processos de trabalho e das práticas de saúde, posto que as ações de saúde são implementadas sobre uma base territorial detentora de uma delimitação espacial previamente determinada (Monken e Barcellos, 2005). A execução das práticas de saúde sobre um substrato territorial já vem sendo utilizada por distintas iniciativas no âmbito do SUS, como a Estratégia Saúde da Família, a Vigilância em Saúde Ambiental, a proposta dos municípios/cidades saudáveis e a própria descentralização prevista na Constituição Federal (Monken e Barcellos, 2005). 
No entanto, por vezes, a estratégia da territorialização em saúde, sobretudo no contexto das ações da Atenção Básica à Saúde, reduz bastante a potência analítica e a eloquência descritiva acerca das inúmeras características da vida das pessoas que emergem num dado território. Em verdade, a operacionalização da categoria 'território' por parte dos profissionais do SUS vem sendo tratada de forma parcial, de modo que o conceito de espaço, consagrado a fins administrativos que se voltam para a dimensão gerencial dos serviços de saúde, tem limitados seu potencial e suas possibilidades na identificação de questões de saúde e das correspondentes iniciativas de intervenção concreta na realidade cotidiana das coletividades humanas.

Para além da dimensão político-operativa do sistema de saúde, o território, na condição de cotidiano vivido no qual se dá a interação entre as pessoas e os serviços de saúde no nível local do SUS, caracteriza-se por uma população específica, vivendo em tempo e espaço determinados, com problemas de saúde definidos, mas quase sempre com condicionantes e determinantes que emergem de um plano mais geral. Esse espaço apresenta, portanto, além de uma delimitação espacial, um perfil histórico, demográfico, epidemiológico, administrativo, tecnológico, político, social e cultural, que o caracteriza como um território em permanente construção (Miranda et al., 2008).

A apreensão e a compreensão do território, em que pese toda a sua riqueza e complexidade, sinalizam uma etapa primordial para a caracterização descritiva e analítica das populações humanas e de seus problemas de saúde. Além disso, também permitem a avaliação dos reais impactos dos serviços sobre os níveis de saúde dessa população, possibilitando, ou efetivamente abrindo, espaços para o desenvolvimento de práticas de saúde voltadas para o chão concreto, para o lugar da vida cotidiana das pessoas. Essa (re)emergência do território como categoria analítica dos eventos saúde-doença não é recente, mas nos convida a novas idéias e a elaborações teóricas e práticas, inspirando-nos a pensar não no território per si, mas em termos dos seus contextos de uso - e aqui se encontram precisamente as possibilidades da construção de interfaces operacionais entre a Atenção Básica à Saúde e a Vigilância em Saúde (Santos, 2008).

A concepção hegemônica de saúde, assentada na centralidade do modelo médico-assistencial e hospitalocêntrico, ainda se faz presente e disputa no processo de construção do SUS. Ela tem levado à impotência crescente e avassaladora do sistema de saúde diante das complexas transformações nos mais diversos 'ambientes' da vida das pessoas, advindos de graves questões relacionadas com os progressivos processos de urbanização e de segregação socioespacial, sobretudo nas complexas regiões metropolitanas brasileiras e de exclusão social ou, como advogam alguns autores, de inclusão precária (Couto, 2008). Também no campo e nas florestas, a expansão do agronegócio em monocultivos e pecuária desterritorializa e insiste em reterritorializar comunidades tradicionais. 
Nesse contexto, vem se fortalecendo o paradigma da promoção da saúde, orientado por ações amplas e coletivas e que requer a intersetorialidade e a transversalidade não mais como esforço de retórica, e sim como concretude das práticas. A atenção voltada para a produção social da saúde das populações gera a necessidade de esclarecer as mediações que operam entre as condições reais em que se reproduzem os grupos sociais no espaço e a produção da saúde e da doença (Monken, 2005).

Tentar compreender o território é, em princípio, assumir a atitude de percorrer diversas e distintas acepções elaboradas acerca dele ao longo dos anos. Inúmeros autores, filiados às mais diferentes tradições intelectuais e correntes de pensamento, intentaram realizar esse percurso, e cada qual, ao seu modo e no seu tempo, contribuiu para a compreensão do mesmo.

Alguns estudiosos tratam de abordar o território para além de sua dimensão conceitual, ou seja, do ponto de vista de uma geografia dita relacional, que ressalta ser o território um dos principais conceitos na tentativa de responder à problemática da relação entre a sociedade e o seu espaço (Eduardo, 2006; Haesbaert, 2006). A polissemia evidenciada no tratamento conceitual do território na literatura, antes de constituir um problema para a sua análise, corresponde, na verdade, ao substancial incremento na capacidade descritiva e analítica do conceito, reunindo múltiplas e diferenciadas tradições de abordagem e de apropriação do território:

Apesar de ser um conceito central para a geografia, território e territorialidade, por dizerem respeito à espacialidade humana, têm certa tradição também em outras áreas, cada uma com um enfoque centrado em uma determinada perspectiva. Enquanto o geógrafo tende a enfatizar a materialidade do território, em suas múltiplas dimensões (que deveria incluir a interação sociedade-natureza), a ciência política enfatiza sua construção a partir de relações de poder (na maioria das vezes, ligada à concepção de Estado); a economia, que prefere a noção de espaço à de território, percebe-o muitas vezes como um fator locacional ou como uma das bases da produção (enquanto 'força produtiva'); a antropologia destaca sua dimensão simbólica, principalmente no estudo das sociedades ditas tradicionais; a sociologia o enfoca a partir de sua intervenção nas relações sociais, em sentido amplo; e a psicologia, finalmente, incorpora-o no debate sobre a construção da subjetividade ou da identidade pessoal, ampliando-o até a escala do indivíduo (Haesbaert, 2006, p. 37).

\section{O território e a Atenção Básica à Saúde no SUS}

A ESF foi proposta, na primeira metade da década de 1990, como mecanismo de reorientação do modelo assistencial, baseando-se no trabalho de equipes multiprofissionais em unidades básicas de saúde. Essas equipes são 
responsáveis pelo acompanhamento de uma 'população adscrita', localizada em uma área delimitada, mediante ações de promoção da saúde, prevenção, recuperação e reabilitação de doenças e de agravos mais frequentes (Andrade, Barreto e Fonseca, 2004).

A ESF possui diferenças marcantes em relação ao modelo hegemônico médico-hospitalocêntrico, tais como: incorporação do conceito de saúde como qualidade de vida e defesa da prestação de serviços de saúde como um direito de cidadania; concentração das ações na coletividade, sem deixar de lado o indivíduo, centrando-se na atenção integral à saúde por meio de ações de promoção, proteção, cura e recuperação; a hierarquização da rede de atendimento em níveis de atenção primária, secundária e terciária, articulados entre si e coordenados pela atenção básica; distribuição dos serviços de saúde no território dos municípios, permitindo o acesso da população às ações de saúde; predomínio da intervenção por equipe multidisciplinar, e com planejamento e programação pautados em dados epidemiológicos e priorizado por famílias ou grupos com maior risco de adoecer e de morrer; estímulo à participação comunitária; e funcionamento baseado na organização da demanda e no acolhimento dos problemas da população adscrita (Andrade, Barreto e Fonseca, 2004).

A despeito das grandes conquistas e diferenças em relação ao modelo hegemônico biomédico, evidenciamos que tais características não são operacionalizadas e percebidas pela comunidade e pelos profissionais de saúde de forma homogênea, ficando claros os seus imensos desafios e contradições, como o forte caráter prescritivo e uma 'confusão' entre o que é ferramenta para o diagnóstico e a intervenção e aquilo que é resultado em saúde. Ou seja, é como se as equipes, ao seguirem a 'prescrição' altamente detalhada das ações programáticas previstas na ESF, lograssem atingir os resultados desejados, com a decantada resolução de aproximadamente $85 \%$ dos problemas de saúde (Franco e Merhy, 2000). Franco e Merhy (2000) ressaltam, ainda, a necessidade de um verdadeiro trabalho em equipe, deixando de lado a onipotência de cada profissional, bem como a incapacidade atual dos profissionais das equipes de saúde da família de 'perceberem' e 'operacionalizarem' o ambiente-território, o que compromete, em muito, a declarada 'potência transformadora' da ESF. Nesse contexto de muitos avanços e conquistas, mas ainda de muitas dificuldades, entendemos que ganha substancial relevo a 'problematização' do território articulada à noção de Vigilância em Saúde.

Nos tempos atuais, a questão ambiental se impõe de forma eloquente, apresentando-se como mais uma 'tarefa' a ser agregada pelos profissionais de saúde, uma vez que são patentes não apenas as inter-relações entre a degradação ambiental e a saúde humana (Ianni e Quitério, 2006), mas também a importância da integridade dos ecossistemas e da preservação da biodiversidade 
para a manutenção dos serviços ambientais e para o suporte ao modo de vida de comunidades tradicionais.

A reorientação dos sistemas de saúde na direção de se afirmarem como 'espaços de saúde' - e não como espaços exclusivos de atenção à doença - exige todo um processo de construção social de mudanças que devem se dar, concomitante e dialeticamente, na própria concepção do processo saúde-doença (Monken, 2005). Para a constituição de uma base organizativa dos processos de trabalho nos sistemas locais de saúde dirigida a essa nova prática e que permita resolver a 'tarefa' de desvelar as relações entre o ambiente e a saúde, reveste-se de significado capital o reconhecimento dos territórios e seus contextos de uso, uma vez que materializam diferentemente as interações humanas e os problemas de saúde:

(...) cabe à vigilância em saúde exercer o papel organizativo dos processos de trabalho em saúde mediante operações intersetoriais articuladas por diferentes ações de intervenção - promoção, proteção e atenção - fincadas em seus três pilares estratégicos: os problemas de saúde, o território e a prática intersetorial (Teixeira, Paim e Vilasbôas, 1998, p. 42).

Muitas vezes, nos diagnósticos das condições de vida e da situação de saúde, os elementos constitutivos da reprodução da vida social nos diversos lugares são listados e tratados como conteúdos desarticulados do território analisado. Tradicionalmente, essas análises de situação são realizadas mediante a delimitação do espaço em determinada escala, buscando-se descrever apenas o seu conteúdo e tratando-se o espaço como mero depositário de determinadas características e aspectos. Uma proposta de saúde baseada no território deve também considerar os sistemas de objetos naturais e construídos e identificar seus diversos tipos de ações e como eles são percebidos pelas populações. Nesse sentido, é importante que o reconhecimento dos contextos de uso se faça por intermédio de métodos que identifiquem suas singularidades e seus problemas (de saúde e ambientais), com base numa abordagem territorial (Monken, 2003).

A territorialização é em um dos pressupostos básicos do trabalho da ESF. No entanto, a tarefa de territorialização adquire, pelo menos, três sentidos diferentes e complementares: demarcação de limites das áreas de atuação dos serviços; reconhecimento do 'ambiente', da população e da dinâmica social existentes nessas áreas; e estabelecimento de relações horizontais com outros serviços adjacentes e verticais, como centros de referência (Pereira e Barcellos, 2006).

No caso da ESF, percebe-se a preocupação de operacionalizar o conceito de território sem que se discutam, no entanto, os seus múltiplos sentidos. Quando se considera um determinado local delimitado pela ESF, pode-se 
falar de uma configuração territorial que possui determinados atributos. Essas características, naturais ou elaboradas pelo homem, dão feição ao ambiente, o qual, por sua vez, influi no processo saúde-doença da população. O reconhecimento dessa relação é passo importante para a incorporação de conceitos e práticas da geografia na ESF (Pereira e Barcellos, 2006). O território, nesse caso, seria mais do que um depositário de atributos da população; seria também o lugar da responsabilidade e da atuação compartilhada.

O SUS se organiza com base num substrato territorial. Com isso, a distribuição dos serviços de saúde assume uma estratégia operacional de demarcação de áreas de abrangência correspondentes aos níveis de complexidade das ações de saúde. As diretrizes organizativas do SUS guardam expressivas relações com a concepção de território enquanto delimitação de uma área específica para cenário das ações de saúde dirigidas a uma população específica, porém com composição distinta, quantitativa e qualitativamente. Nesses territórios, as práticas de saúde convergem para a integração das ações de atenção, promoção e prevenção, de modo que as intervenções sobre os problemas sejam também sobre as condições de vida da população. A organização espacial dos serviços de saúde baseia-se nos princípios da regionalização e da hierarquização, definindo uma base territorial formada por agregações progressivas, tais como a base de atuação dos agentes comunitários de saúde - as microáreas -, a das equipes de saúde da família - as áreas -, e, por fim, a área de abrangência das unidades básicas de saúde (Mendes, 2002).

No campo da saúde pública no Brasil, as práticas de saúde mais próximas do cotidiano da vida das comunidades são aquelas vinculadas às atividades da Atenção Básica à Saúde, concretamente estabelecidas pela ESF. Essa política representa uma reorientação do modelo assistencial de saúde e aponta modos de 'fazer' vigilância em saúde baseados nas seguintes características: estabelecimento de vínculos e de corresponsabilização entre a equipe de saúde e a comunidade; a família, compreendida em seu contexto relacional com o ambiente onde vive, como objeto de atuação e intervenção; a responsabilização sanitária por uma população adscrita ou 'territorializada'; e as práticas extramuros direcionadas para o território (Brasil, 1997).

A construção de instrumentos e ferramentas que permitam uma aproximação ao território de atuação das equipes de saúde da família para levar a termo as ações programáticas previstas na ESF e, para além delas, a consecução de efetivas ações de vigilância em saúde vêm assumindo importante papel e representam hoje grande desafio. O reconhecimento da fragilidade das análises parciais possibilitadas pelo Sistema de Informações da Atenção Básica à Saúde (Siab), cuja unidade básica de análise é a família, requer o avanço dos estudos nessa área para além do 'ambiente' da família e, principalmente, para o 'ambiente' da vida cotidiana da família - em outras palavras, para o território. Assim, o processo contínuo de territorialização 
deve buscar ir além do mapeamento inicial e da delimitação estanque dos territórios, contemplando permanentemente as distintas dinâmicas que emergem de cada território. Entre essas dinâmicas, estão, por exemplo, a chegada de novos processos produtivos e tecnológicos - os quais, ainda que atendam a determinados interesses sociais, são portadores e viabilizadores de numerosas possibilidades de geração de riscos e de ampliação de vulnerabilidades. Nesses contextos, além da ocorrência de danos e agravos à saúde humana, há também prejuízos aos ecossistemas prestadores de serviços ambientais relevantes para toda a comunidade de vida local.

Sobre esse aspecto, entendemos que a problemática ambiental (dentre outras relevantes dimensões existenciais dos territórios) vem sendo tratada de forma absolutamente insuficiente no que tange à necessidade do Siab de apreender e compreender algumas características fundamentais para a análise do socioespaço, pois os únicos 'parâmetros' ambientais presentes nesse sistema (Ficha A) estão relacionados ao 'ambiente' do domicílio das famílias e ao seu entorno mais imediato, e levantam questões como: tipo de casa - tijolo/adobe, taipa revestida, taipa não revestida, madeira, material aproveitado, número de cômodos, energia elétrica; destino do lixo - coletado, queimado, enterrado, céu aberto; tratamento da água no domicílio - filtração, fervura, cloração, sem tratamento; abastecimento de água - rede geral, poço ou nascente; destino de fezes e urina - sistema de esgoto, fossa, céu aberto (Brasil, 2000). Entretanto, esses parâmetros não destacam questões como a do lançamento de efluentes industriais e de outros resíduos oriundos dos mais diversos processos produtivos, por vezes localizados a grandes distâncias, mas que distribuem os malefícios de suas atividades de forma desigual e injusta, ao contaminarem continuamente os recursos hídricos de usufruto comum de determinada comunidade, para ficarmos apenas em um exemplo mais imediato e óbvio.

Estamos falando, portanto, da possibilidade concreta de contaminação ambiental e das pessoas por substâncias químicas absolutamente estranhas aos lugares da vida cotidiana onde irão exercer seus efeitos tóxicos, sejam esses imediatos ou de longo período de latência, atualmente não contemplada no formato corrente dos sistemas de informação em saúde. Esse fato comprova a necessidade urgente de uma nova forma de 'vigilância em saúde' que leve a problematização da saúde com base no território e nos seus contextos de usos e de disputas pelos mais variados projetos. E isso evidencia a relevância da opinião das pessoas que vivem nos territórios para a efetivação real de uma 'vigilância em saúde' conectada à dinâmica das transformações do território.

Em recente trabalho (Santos, 2008), evidenciou-se a 'distância' existente entre a análise 'prescrita' do território pela ESF e as reais condições de vida da população analisada. No estudo, ficaram patentes as muitas e pro- 
fundas necessidades de saúde não incluídas no rol das ações programáticas das equipes de saúde, mas ricamente captadas pelas entrevistas. Ficou clara, ainda, a problemática surgida a partir da realização da territorialização em saúde sem a garantia da cobertura 'territorial' mínima e integral das microáreas e áreas por equipes de agentes comunitários de saúde e saúde da família. Isso não significa dizer que, por sua vez, a existência de uma cobertura dita 'ideal' (de 2.400 a 4.000 pessoas, com média de 3.000 pessoas) (Brasil, 2006) poderá solucionar os problemas de saúde da comunidade, sobretudo aqueles ligados à baixa qualidade do ambiente urbano e aos seus desdobramentos para a saúde humana.

Assim, toda e qualquer proposta de vigilância em saúde deve estar atenta às múltiplas forças e fluxos que perpassam os territórios e interagem de forma diferenciada sobre eles, condicionando e determinando novas formas de adoecer e de morrer que se traduzem em graves e complexas e repercussões a serem resolvidas pelo SUS e pela sociedade tomada de forma ampla.

\section{Sublinhando as relações produção, trabalho, ambiente e saúde no território}

A importância das relações entre os processos de produção e consumo e a saúde humana vem sendo intensamente estudada, debatida e reconhecida na área da saúde coletiva, especialmente nos campos da saúde ambiental e da saúde do trabalhador.

Da perspectiva do território, cabe reconhecer os processos produtivos nele instalados, bem como os que se situam em seu entorno, ou mesmo remotamente, e identificar suas relações com o ambiente e com a saúde dos trabalhadores e dos moradores. A Figura 1 mostra de forma esquemática essas relações, mediante um hipotético processo produtivo de bens, serviços ou infraestrutura. Esse processo vai demandar inputs que podem envolver a ocupação de um espaço - normalmente já ocupado por comunidades humanas ou por outras comunidades de vida (fauna, flora) - que seja, inclusive, um ponto de disputa e conflito no território. Podem envolver, ainda, o consumo de água - em volumes que cheguem a comprometer o abastecimento humano, no caso de as fontes serem as mesmas -, de energia e de combustíveis fósseis. Frequentemente envolvem o transporte de matérias-primas, impactando no volume de tráfego em estradas e vias públicas, com a possibilidade de aumento de acidentes - atropelamentos, colisões - ou de contaminação do ambiente com substâncias químicas perigosas.

No interior do processo produtivo, efetua-se o processo de trabalho, que envolve diretamente a saúde dos trabalhadores e pode ser fonte de renda e de bem-estar, oportunidade de socialização e realização, mas também pode ser espaço de exploração, sofrimento, contaminação e acidentes, a depender 
das relações, condições e formas da organização do trabalho, que também são objeto da Vigilância em Saúde.

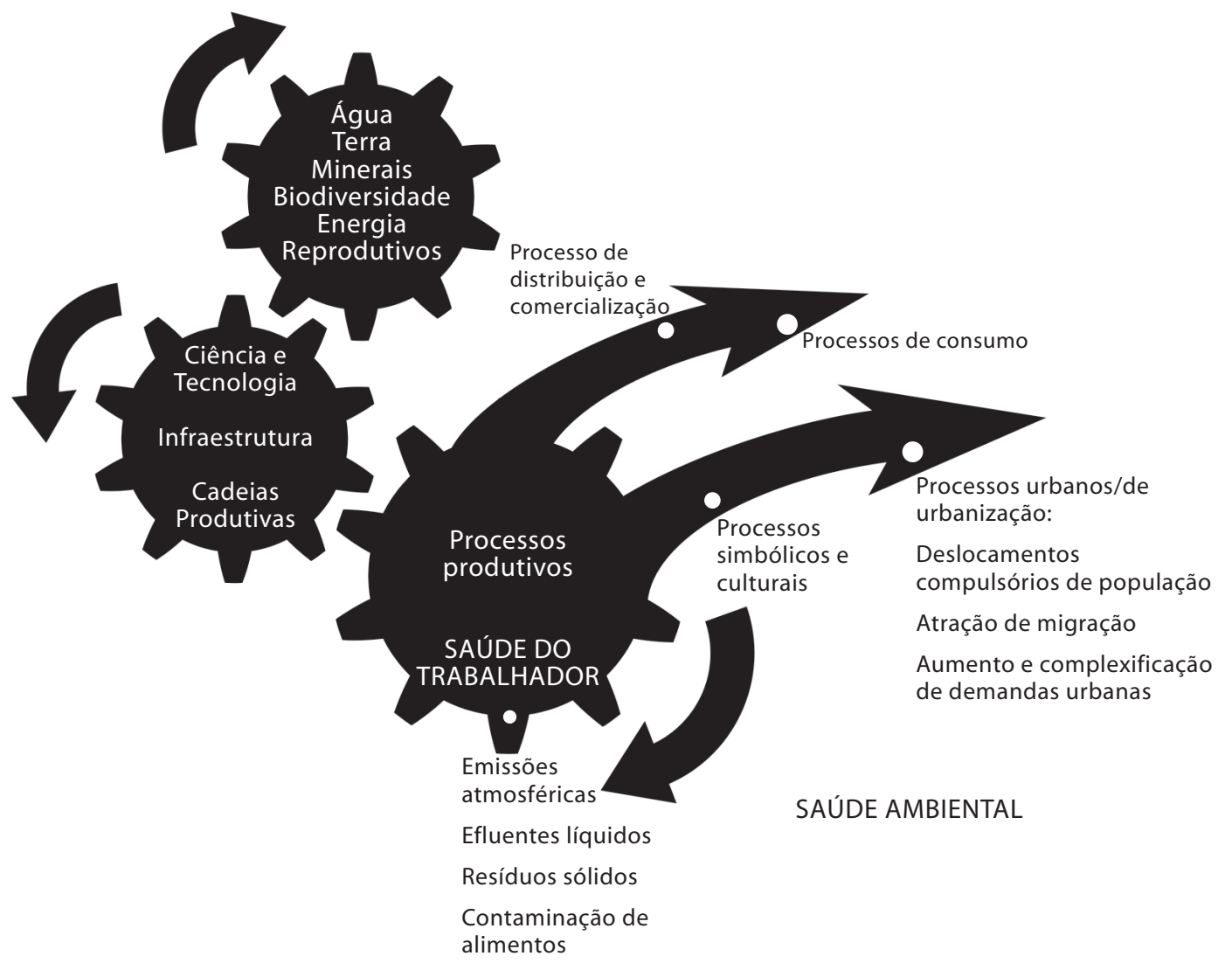

Fonte: Os autores.

Como output desse processo produtivo, estão as mercadorias, os serviços ou as infraestruturas que podem exigir vigilância; além disso, em determinados casos, é possível que suas embalagens disseminem riscos para outros territórios. Pode haver também resíduos sólidos, efluentes líquidos e emissões atmosféricas, os quais, se não forem tratados e destinados adequadamente, podem vir a contaminar águas superficiais e subterrâneas, o solo, o ar e os alimentos no território da comunidade, causando impactos na saúde, na segurança alimentar, nas atividades econômicas de subsistência etc. Ainda 
como output, podemos ver as unidades produtivas como centros geradores e difusores de uma cultura diferente daquela da comunidade, não só no que diz respeito às noções de tempo, disciplina, hierarquia nas relações sociais e consumo, mas também a valores, como a competitividade, que vão influenciar os modos de subjetivação do grupo social, as identidades coletivas etc.

Assim, é de fundamental importância que a equipe de saúde responsável pelo território esteja atenta e capacitada para identificar esses processos produtivos no território - e em outras escalas geográficas - e suas relações com o ambiente e a saúde locais, mas que também abra os olhos para as relações do território com o sistema-mundo, como conceitua Milton Santos (1999), a fim de não perder de vista que no contexto da globalização e do capitalismo tardio, os territórios são predominantemente 'territórios-rede', permeados por fluxos de diversas naturezas, externos a suas fronteiras, que o conectam ao mesmo tempo a inúmeras redes também externas ao seu espaço. Assim como as comunidades, os territórios não são ilhas (Rigotto, 2008, p. 75).

\section{Alguns passos para compreender o processo saúde-doença na dinâmica viva dos territórios}

Um profissional ou uma equipe de saúde da família chega a uma nova unidade. Na mente, a ideia de que, para inverter o modelo de atenção à saúde no SUS, é preciso 'ver' a dinâmica do processo saúde-doença no território, é preciso conhecer o território, é preciso ter vínculos com o território (e, para isto, claro, é preciso ter condição de trabalho formalizada, estável, digna, valorizada...).

Como se aproximar do território para conhecê-lo? O que é importante saber? Onde encontrar as informações? Em que medida esse pode ser um processo participativo, construído em diálogo com a comunidade?

Embora cada situação seja singular, apresentamos a seguir alguns passos que podem ajudar a orientar a abordagem do território pelas equipes de saúde.

As questões abordadas nos itens 1 e 2 podem ser investigadas com base em diferentes instrumentos: dados secundários e de literatura, aplicação de questionários, realização de grupos focais ou de rodas de conversa sobre os temas, entrevistas com informantes-chave, elaboração de mapas pelos moradores etc.

\section{1) $O$ que já se sabe sobre este lugar?}

Sempre é possível encontrar conhecimentos já produzidos sobre o território em estudo - se não exatamente, pelo menos sobre o município, a região; com isso, reduz-se muito o tempo da etapa de aproximação. 
Interessa conhecer a história do lugar, porque ela já vai adiantar muitos elementos do que chamamos de identidade territorial, a qual está, às vezes, fortemente presente na identidade coletiva. Compreender a linha que une o passado ao presente nos permitirá aceder a potencialidades, tradições, cultura, valores e hábitos, e também aos possíveis conflitos - de poder, de uso e ocupação do solo, culturais, étnicos, ambientais etc. -, todos da maior relevância para a saúde.

Certamente o ecossistema local se expressará nessa história, e vale buscar a descrição de suas características, a forma como a comunidade se relacionou com ele ao longo do tempo, os serviços ambientais que vem prestando, o seu estado de saúde...

Esse tipo de informação pode ser buscado na bibliografia - às vezes, a biblioteca municipal nos ajuda mais do que a internet -, nas escolas e com professores da comunidade, idosos, moradores antigos etc.

Podemos também, desde já, apropriar-nos de dados sobre a população e seu perfil - sexo, idade, composição étnica, escolaridade, ocupação etc.; sobre indicadores de saúde - morbi-mortalidade, saneamento básico etc.; além de mapas do território.

Muitas vezes esses dados já estão disponíveis na prefeitura, na regional administrativa ou com os agentes comunitários de saúde, mas podem também ser encontrados em bancos de dados, como os do Instituto Brasileiro de Geografia e Estatística (IBGE) e o Departamento de Informática do SUS (Datasus), entre outros - embora nem sempre com o recorte microespacial desejado.

Esse conjunto de informações pode ser compartilhado com a equipe de saúde da família que está estudando o território, para que se construa uma imagem coletiva prévia, registrando-a no 'caderno de campo'.

\section{2) Pondo o pé no chão e a mão na massa}

Muito deve ser cuidada a maneira de chegar ao território. Escolher bem os primeiros contatos é fundamental para encontrar informantes realmente 'chave', que podem abrir portas de novas redes de contato e de novas visões sobre o lugar. Abordar previamente alguém que conheça bem a comunidade, inclusive os profissionais de saúde que nos antecederam na unidade, quando for o caso, pode ajudar bastante na obtenção dessas referências.

Embora muitas vezes uma imagem de homogeneidade e harmonia esteja associada à palavra comunidade, é prudente levar em consideração a possibilidade de haver atores com interesses distintos. Lembrar que a comunidade "é um espaço comum de recursos, sim, só que exposto a distintos projetos, interesses, formas de apropriação e uso material e simbólico" (Acselrad, 2004, p. 124) 
É preciso cuidar também da postura da equipe. E isso envolve um amplo leque de habilidades comunicacionais e relacionais: a linguagem, a apresentação, o desejo de escuta, o respeito pela diferença, a astúcia.

É muito desejável que se possa estruturar um grupo para estudo do território, envolvendo profissionais de saúde, lideranças e moradores locais. O convite deve ser feito pela explicitação da intenção de conhecer o lugar para melhor elaborar as ações de saúde, e sua participação certamente trará mais acuidade, adequação e força às futuras ações.

O grupo deve então construir sua proposta de trabalho: a que perguntas querem responder, como vão buscar essas respostas e compartilhar os elementos que vão encontrando, como as tarefas serão divididas, quais os prazos etc.

Mais uma vez, há que dar lugar às singularidades de cada contexto sócio-histórico específico, aos fluxos mais amplos que o perpassam e às suas potencialidades criadoras. A título de orientação, os seguintes elementos podem ser contemplados no estudo do território - na prática, observa-se que essa divisão em dimensões e temas é artificial, e que todos eles estão inter-relacionados:

\section{a) A comunidade humana e as políticas públicas}

- origens, características demográficas, distribuição no socioespaço, segmentos e subgrupos, cultura;

- condições socioeconômicas: de que se ocupam as pessoas que vivem aqui? como a renda se forma? como é distribuída?;

- organização social e política: sujeitos coletivos, processos de mobilização, lideranças, associações e grupos, temas e objetos de ação;

- qualidade e condições de vida: moradias, espaços públicos, alternativas de lazer, padrões alimentares;

- as políticas públicas e projetos comunitários: como as políticas de educação, saúde, trabalho, meio ambiente, transporte, cultura e lazer, entre outras, estão acontecendo no território? quais os equipamentos públicos disponíveis? que iniciativas inovadoras estão em desenvolvimento? quais os desafios e problemas? como está o saneamento ambiental - abastecimento de água, esgoto doméstico e industrial, resíduos sólidos domésticos, urbanos, industriais e sanitários, drenagem urbana? como vêm sendo acompanhadas a segurança e a qualidade dos alimentos e da água?.

\section{b) $O$ 'ambiente': ecossistema(s) e paisagem(ns) modificados}

- meio físico: unidades de paisagem, condições geológicas e topográficas, águas superficiais e profundas, drenagem; clima: meteorologia, temperatura, ventos e umidade; 
- meio biológico: como se compõem a fauna e a flora locais? há espaços naturais preservados, áreas verdes protegidas?;

- dinâmicas ambientais: relações da comunidade com os serviços ambientais;

- uso do solo e mobilidade: localização das áreas residenciais, agrícolas, industriais e comerciais, e dos depósitos de resíduos; formas de deslocamento e vias de transporte.

\section{c) Processos de produção no território (e os fluxos que o perpassam)}

Este item engloba as atividades econômicas que ocorrem no território e em seu entorno tendo em vista a relevância de seus impactos sobre a saúde da população e dos ecossistemas.

Interessa detalhar os ramos e gêneros de produção agrícola, industrial e de serviços, sejam eles formais ou informais, bem como as obras de infraestrutura e as cadeias produtivas instaladas no território. Devem merecer atenção especial eventuais projetos de 'desenvolvimento' em implantação ou previstos para o lugar, especialmente pela possibilidade de atuação preventiva em relação a eles, antecipando e eliminando riscos à saúde.

É preciso, ainda, construir mapeamentos da localização dessas atividades, os quais nos permitam apreciar o conjunto que as atividades conformam e a pressão que elas exercem sobre a capacidade de suporte do ambiente, suas relações com áreas naturais, recursos naturais e grupos de moradores no entorno.

Dependendo do tipo e do porte da atividade, pode ser necessário um amplo conjunto de informações cuja apropriação muitas vezes demanda o diálogo com profissionais, instituições e entidades de outras áreas. Em geral, o órgão ambiental estadual ou municipal deve dispor de, e disponibilizar, informações relevantes para a equipe de saúde, inclusive Estudos de Impacto Ambiental (EIA) e Relatórios de Impacto sobre o Meio Ambiente (Rima), quando for o caso. Os profissionais da vigilância ambiental do município podem ter dados sobre problemas que já estejam acompanhando, mas essa informação pode, e deve, ser complementada por depoimentos de trabalhadores e vizinhos dos empreendimentos, que exercem a vigilância cotidiana.

Para o estudo do processo de trabalho de cada unidade produtiva, pode-se tomar como referência um roteiro específico, como o constante do Quadro 1, que deve ser adaptado às características de cada gênero de atividade e local.

Para tanto, é necessário que o grupo adentre esses espaços de produção e trabalho, a fim de colher informações junto de informantes-chave (gerentes, engenheiros, encarregados, responsáveis pelo setor de recursos humanos ou pelo almoxarifado etc.) e para realizar observação direta do processo de 
trabalho. É sempre recomendável, entretanto, ouvir antes os trabalhadores da empresa, pois eles podem alertar para aspectos que é importante observar, e consultar a literatura científica sobre os riscos relacionados àquele processo produtivo.

\section{Quadro 1}

Roteiro para estudo dos processos de trabalho em sua relação com o ambiente interno e externo

1. Identificação da empresa: razão social, localização, ramo de atividade.

2. Aspectos históricos da organização da empresa: origens da empresa e do capital, procedência, evolução, unidades; razões da instalação neste local e data; situação atual. produção e mercado consumidor.

3. Trabalhadores e relações de trabalho: procedência, número, distribuição por sexo e idade, escolaridade, treinamento para a função, absenteísmo; critérios para seleção; avaliação de desempenho; formas de contrato de trabalho; remuneração e benefícios; jornada de trabalho.

\section{Instalações da empresa}

5. Processo de produção: matérias-primas, meios de produção, fluxograma, processos auxiliares e/ou paralelos, situações de transtorno, subprodutos, produtos finais, resíduos.

6. Organização do trabalho: divisão do trabalho; conteúdo das tarefas; formas de organização do trabalho; controle de ritmo, produtividade e modo operatório; relações sociais na empresa.

7. Condições ambientais de trabalho e atenção à saúde: riscos físicos, químicos, biológicos, ergonômicos e de acidentes - natureza, dose, fontes, pontos críticos; medidas de proteção individual e coletiva - adequação, manutenção, eficácia, uso efetivo; política de assistência médica; campanhas e ações educativas; ações em segurança e saúde no trabalho; existência e funcionamento da comissão interna de prevenção de acidentes (Cipa), do Serviço Especializado em Segurança e Medicina do Trabalho (SESMT), do Programa de Controle Médico em Saúde Ocupacional (PCMSO) e do Programa de Prevenção de Riscos Ambientais (PPRA); dados epidemiológicos sobre doenças e acidentes.

8. Relação com o meio a mbiente: área - recursos físicos e espaço ocupado; consumo de água, energia elétrica e combustíveis; dissipações de calor - chaminé, gases quentes, vapor d'água, fornos, caldeiras, reatores, cinzas quentes, material quente, fluido refrigerante, torres de condensação; poluentes do ar produtos da combustão, gases combustíveis residuais, emanações de substâncias químicas - formas de captação e tratamento; poluentes da água - vazamentos de tanques, dutos, canalizações, válvulas, bacias, valas e canaletas; borras e lamas; efluentes líquidos; descarte de fluidos; saídas líquidas das estações de tratamento de esgotos e de despejos industriais - dimensionamento e adequação do tratamento; poluentes do solo - resíduos sólidos, aparas e sucatas, borras, cinzas e poeiras coletadas, embalagens utilizadas - tratamento e destinação; geração de ruído; transporte de matérias-primas e de produtos finais - eixos; coletividades humanas concernidas - vizinhos e transeuntes.

9. Relações institucionais: com o município, o Estado, órgãos fiscalizadores do trabalho e do ambiente, o sindicato dos trabalhadores.

Fonte: Os autores.

Identificados os riscos ocupacionais e/ou ambientais, é preciso conhecer quem são os expostos a eles dentro e fora da empresa e os elementos que compõem sua vulnerabilidade: sexo, idade, raça, grupos especiais, local de moradia e de trabalho, escolaridade, características socioeconômicas, formas de exposição - vias, intensidade e frequência etc. 
Algumas empresas - particularmente aquelas cujos processos produtivos envolvem substâncias químicas tóxicas, inflamáveis ou explosivas, radiações ionizantes ou outros fatores capazes de gerar acidentes ampliados - devem dispor de uma política de comunicação de risco e de um plano de emergência, elaborados de forma transparente e participativa, e bem apropriados pela comunidade.

É fundamental ainda conhecer de que se ocupam os/as demais trabalhadores/as que vivem no território e que transitam por outras áreas da cidade ou da região a fim de exercerem suas atividades de trabalho. Essas pessoas também devem ser acolhidas na Atenção Básica à Saúde, em seu local de trabalho ou de moradia, seja como cidadãos/ãs, seja em sua condição específica de trabalhador/a, muitas vezes exposto/a a riscos à saúde que precisam ser identificados, eliminados ou mitigados, e cuja saúde precisa ser monitorada, visando à informação que viabiliza a busca da proteção, o diagnóstico precoce de alterações e o exercício e acesso a direitos trabalhistas e previdenciários, além dos civis.

Um instrumento importante para isso é a história do trabalho, que pode ser reconstruída em grupos homogêneos de trabalhadores/as (envolvidos num mesmo processo de trabalho) ou individualmente, na moradia dos mesmos, ou, ainda, na unidade de saúde, como proposto no manual sobre doenças relacionadas ao trabalho do Ministério da Saúde (Brasil, 2001). A história do trabalho deve ser incorporada rotineiramente ao acolhimento na unidade de saúde e à anamnese clínica. Por fim, deve-se lembrar sempre que é preciso estar atento a riscos ambientais que podem estar atingindo a comunidade $\mathrm{e}$ que são originados em outros territórios, tendo em vista a mobilidade dos riscos, que cada vez se amplia mais: poluentes do ar podem ser trazidos pelo vento, contaminantes da água podem vir através dos rios, os do solo podem ser trazidos para zonas de descarga de resíduos sólidos, pelas vias de transporte ou por dutos; e os da mente, pela mídia... Processos de consumo também podem estar envolvidos na geração de riscos ambientais, como é o caso dos produtos domissanitários ou da geração de resíduos sólidos. Assim, a inter-relação com áreas e processos vizinhos e remotos também deve ser considerada.

\section{d) Os conflitos socioambientais e a percepção da comunidade}

Quais os conflitos em curso no território? As disputas pelo uso e ocupação da terra e do solo urbano, o acesso aos recursos naturais, a contaminação e a qualidade ambiental, as relações políticas e sociais etc.

Quais os problemas em curso no território percebidos pelos diferentes grupos da população? Como esses atores os explicam e propõem solucionálos? Estabelecem relações entre esses problemas e a saúde? Quais consideram prioritários para a intervenção/ação? 
Que recursos, forças e caminhos as pessoas percebem na própria comunidade? Que projetos de futuro estão se conformando?

Evidentemente, esses elementos mais profundos vão surgindo a partir da aproximação progressiva das pessoas, dos processos coletivos de apropriação de informações e do debate sobre os problemas. Eles também podem ser investigados por meio de questionários, entrevistas em profundidade e trabalhos em grupo, inclusive com o apoio de técnicas de educação popular - como o sociodrama, o teatro, os mapas falados etc.

\section{Considerações finais}

A ampliação do olhar dos profissionais da Atenção Básica à Saúde sobre o território é estratégica para: a superação dos limites da unidade de saúde e das práticas do modelo de atenção convencional; a (re)construção do vínculo dos profissionais e do sistema de saúde com o lugar; a adequação das ações de saúde à singularidade de cada contexto sócio-histórico específico; e a incorporação efetiva do paradigma da promoção da saúde e da participação. Não é uma panaceia, mas é um ponto de partida fértil.

As questões de saúde do trabalhador e de saúde ambiental estão no cotidiano de pessoas, famílias, comunidades e grupos sociais, exercendo relevante influência na qualidade de vida, no adoecer e no morrer dos segmentos sociais. O sistema público de saúde precisa avançar nos esforços que vem fazendo para contemplar essas dimensões no cotidiano dos serviços, desde o nível primário.

A proposta de territorialização aqui esboçada representa, obviamente, um esforço de conhecimento do território que vai muito além do tradicional processo de territorialização que vem sendo implementado na Atenção Básica à Saúde e na ESF. A proposta, em construção, demanda muito mais tempo da equipe e o envolvimento ativo e dialógico de todos os seus profissionais. Demanda, também, conteúdos, habilidades e atitudes nem sempre oferecidas nos tradicionais processos de formação na área da saúde. É permanente e processual: sempre haverá o que conhecer na dinâmica das territorialidades. Supõe, ainda, uma compreensão ampliada do processo saúde-doença na complexidade dos sociosespaços contemporâneos, e do papel do Estado na garantia do direito à saúde. Supõe também, é claro, que as questões básicas de direitos trabalhistas e condições de trabalho estejam equacionadas no sistema. Demanda, certamente, além disso, outra organização do trabalho na Atenção Básica à Saúde, e uma reestruturação ou complementação da atenção básica, a exemplo do que vem sendo feito pelos Núcleos de Apoio à Saúde da Família (Nasf), ampliando o leque de profissionais dedicados à relação com o território. 
Por outro lado, dialeticamente, é um potente caminho para planejar ações de promoção e de atenção integral à saúde, porque oferece a elas um chão muito concreto como base: os projetos de saúde nascem das necessidades de saúde da comunidade, e não de programas verticais que vêm do 'nível central' para a 'ponta'. E porque, de per si, é já uma forma de produzir e difundir conhecimento, mobilizar, educar, criar ou fortalecer redes, empoderar sujeitos coletivos e projetos de equidade e sustentabilidade, ou seja, de construir saúde. O convite é para darmos passos nesse sentido, testando e aperfeiçoando esse esboço de proposta.

\section{Contribuições dos autores}

Alexandre Lima Santos procedeu ao estudo bibliográfico, redigiu parte do texto e participou da discussão da proposta; Raquel Maria Rigotto elaborou a proposta de territorialização e redigiu parte do texto.

\section{Notas}

1 Médico do Programa de Saúde da Família (PSF) de Fortaleza, Ceará, Brasil. Mestre em Saúde Pública, pela Universidade Federal do Ceará (UFC). <alexandredelimasantos1@gmail.com> Correspondência: Rua Professor Costa Mendes, n. ${ }^{\circ} 1.608,5^{\circ}$ andar, CEP 60431-970, Fortaleza, Ceará, Brasil.

2 Professora do Departamento de Saúde Comunitária, Faculdade de Medicina, Universidade Federal do Ceará. Doutora em Sociologia pela Universidade Federal do Ceará (UFC), Fortaleza, Brasil. <raquelrigotto@gmail.com> 


\section{Referências}

ACSELRAD, Henri. Justiça ambiental e cidadania. Rio de Janeiro: Relume Dumará; Fundação Ford, 2004.

ANDRADE, Luiz Odorico Monteiro de; BARRETO, Ivana Cristina de Holanda Cunha; FONSECA, Cláudio Duarte da. A estratégia de saúde da família. In: DUNCAN, Bruce B.; SCHMIDT, Maria Inês; GIUGLIANI, Elsa R. J. (Org.). Medicina ambulatorial: condutas de atenção primária baseada em evidências. 3. ed. Porto Alegre: Artmed, 2004. p. $88-101$.

BRASIL. Ministério da Saúde. Doenças relacionadas ao trabalho: manual de procedimentos para os serviços de saúde. Brasília, DF: Ministério da Saúde, 2001.

Ministério da Saúde. Saúde da família: uma estratégia para reorientação do modelo assistencial. Brasília, DF: Ministério da Saúde, 1997.

Ministério da Saúde. Secretaria de Atenção à Saúde. Departamento de Atenção Básica. Política Nacional da Atenção Básica. Série A. Normas e manuais técnicos. 2. ed., 1. reimp. Brasília, DF: Ministério da Saúde, 2006. (Pactos pela Saúde, 4).

Ministério da Saúde. Secretaria de Políticas de Saúde. Departamento de Atenção Básica. Manual do Sistema de Informações da Atenção Básica (Siab). Brasília, DF: Departamento de Atenção Básica, Secretaria de Políticas de Saúde, Ministério da Saúde, 2000.

COUTO, Aiala Colares de O. A cidade dividida: da inclusão precária à territorialização perversa. 2008. Disponível em: $<$ www.webartigos.com/articles/4155/1/ A-Cidade-Dividida-Da-Inclusao-Precaria-aTerritorializacao-Perversa/paginal.html/ print/4155>. Acesso em: 29 out. 2010.

EDUARDO, Márcio F. Território, trabalho e poder: por uma geografia relacional. Campo-
Território: Revista de Geografia Agrária, v. 1, n. 2, p. 173-195, ago. 2006.

FRANCO, Túlio; MERHY, Emerson. PSF: contradições e novos desafios. In: CONFERÊNCIA NACIONAL DE SAÚDE ON-LINE. Tribuna Livre. São Paulo: Conferência Nacional de Saúde, 2000. Disponível em: $<$ www.datasus.gov.br/cns/cns.htm $>$. Acesso em: 27 maio 2007

GONDIM, Grácia Maria de Miranda et al. O território da saúde: a organização do sistema de saúde e a territorialização. In: MIRANDA, Ary Carvalho de et al. (Org.). Território, ambiente e saúde. Rio de Janeiro: Editora Fiocruz, 2008. p. 237-255.

HAESBAERT, Rogério. O mito da desterritorialização: do 'fim dos territórios' à multiterritorialidade. 2. ed. Rio de Janeiro: Bertrand Brasil, 2006.

IANNI, Aurea Maria Zöllner; QUITÉRIO, Luiz Antonio Dias. A questão ambiental urbana no Programa de Saúde da Família: avaliação da estratégia ambiental numa política pública de saúde. Ambiente e Sociedade, v. 9, n. 1, jan.-jun. 2006.

MENDES, Eugênio V. Uma nova agenda para a saúde. São Paulo: Hucitec, 2002.

MONKEN, Maurício. Desenvolvimento de tecnologia educacional a partir de uma abordagem geográfica para a aprendizagem da territorialização em vigilância em saúde. Tese (Doutorado em Saúde Pública) - Escola Nacional de Saúde Pública, Fundação Oswaldo Cruz, Rio de Janeiro, 2003.

MONKEN, Maurício; BARCELLOS, Christovam. Vigilância em saúde e território utilizado: possibilidades teóricas e metodológicas. Cadernos de Saúde Pública, Rio de Janeiro, v. 21, n. 3, p. 898-906, maio-jun. 2005.

PEREIRA, Martha Priscila Bezerra; BARCELLOS, Christovam. O território no Programa 
de Saúde da Família. Hygeia, Revista Brasileira de Geografia Médica e da Saúde, Uberlândia, v. 2, n. 2, p. 47-55, jun. 2006.

RIGOTTO, Raquel Maria. Desenvolvimento, ambiente e saúde: as implicações da (des)localização industrial. Rio de Janeiro: Editora Fiocruz, 2008.

SANTOS, Alexandre Lima. A comunidade do mangue do bairro Vila Velha, Fortaleza/CE: o território e o cotidiano vivido a partir da perspectiva dos moradores e dos profissionais do Programa de Saúde da Família (PSF). Dissertação (Mestrado em Saúde Pública) - Faculdade de Medicina, Universidade Federal do Ceará (UFC), Fortaleza, 2008.
SANTOS, Milton. A natureza do espaço: espaço e tempo, razão e emoção. 3. ed. São Paulo: Hucitec, 1999.

TEIXEIRA, Carmem Fontes; PAIM, Jairnilson Silva; VILASBÔAS, Ana Luiza. SUS: modelos assistenciais e vigilância da saúde. Iesus, Brasília (DF), v. 7, n. 2, abr.-jun. 1998.

Recebido em 09/08/2010

Aprovado em 10/09/2010 